\title{
Late Diagnosis of Anorectal Malformations in Children
}

\author{
Sejdi Statovci, Salih Grajçevci, Murat Berisha, Gani Çeku, Isber Ademaj, Kujtim Ukeperaj \\ Clinic of Pediatric Surgery, University Clinical Centre of Kosovo, Prishtina, Kosovo \\ Email: sejdistatovci@yahoo.com
}

Received 27 February 2015; accepted 18 March 2015; published 19 March 2015

Copyright (C) 2015 by authors and Scientific Research Publishing Inc.

This work is licensed under the Creative Commons Attribution International License (CC BY). http://creativecommons.org/licenses/by/4.0/

(c) (7) Open Access

\begin{abstract}
Anorectal malformations (ARM) include a wide spectrum of congenital defects of the anus, anal canal and rectum, which are often associated with congenital anomalies of other organ systems. They appear with different clinical presentations ranging from simple imperforate anal membrane to very complex defects. They are usually detected immediately after birth or early at neonatal age, but some patients with the milder defects are diagnosed at a later age. Objectives: The aim of this study is to analyze the incidence of patients with ARM diagnosed after neonatal period, clinical features and consequences of delayed diagnosis. Materials and Methods: Since 2010 we performed a combined retrospective and prospective analysis of a total of 76 patients with anorectal malformations, diagnosed and treated at our clinic between 2005 and 2014 . We analyzed patients' age at the time of diagnosis, sex, type of defect, associated anomalies and postoperative functional outcome. Results: 18 patients with ARM $(23.68 \%)$ were diagnosed beyond the neonatal period. Of them 11 were female $(61.11 \%)$ and 7 male patients $(38.89 \%)$. The earliest diagnosed patient was a male of three months of age, while the latest diagnosed patient was a female of 8.5 years of age. All patients had low type anomalies, presented with anal stenosis (16), perineal fistula (1) and vestibular fistula (1). Six patients (33.33\%) were also diagnosed with associated anomalies. Conclusion: High incidence of delayed diagnosis of ARM highlights the importance of a careful, comprehensive clinical examination of the perineum of newborns. All patients with severe and chronic constipation must be evaluated for eventually missed diagnosis of low type anorectal malformations.
\end{abstract}

\section{Keywords}

Delayed Diagnosis, Anorectal Malformations, Constipation

\section{Introduction}

Anorectal malformations (ARM) include a wide spectrum of congenital defects of the anus, anal canal and rec-

How to cite this paper: Statovci, S., Grajçevci, S., Berisha, M., Çeku, G., Ademaj, I. and Ukeperaj, K. (2015) Late Diagnosis of Anorectal Malformations in Children. Surgical Science, 6, 143-148. http://dx.doi.org/10.4236/ss.2015.63023 
tum, which are often combined with urogenital tract defects and associated with other congenital anomalies. Their estimated incidence is 1 per 2000 - 5000 live births [1] [2]. According to Wingspread classification, ARM used to be classified into low, intermediate, or high type, depending upon whether the blind end of the bowel was located below, within, or above the levatorsling [3]. Since 2005, classification of Krickenbeck [1] [3] is widely used not only in establishing the diagnosis of different types of ARM but also for assessment of the outcome after treatment. The diagnosis of ARM should be easily established by careful clinical examination of the perineum in the newborn children and X-ray study within 24 hours of birth. However, in some patients with low type of ARM, diagnosis is not established after birth but at a later age. While for high-type defects, colostomy is recommended at birth, low-type defects can be treated in the period between birth and six months of age [4], depending on the type of the defect and sex. Consequently, missing the diagnosis at the right time means the delayed treatment which can lead to increased surgical and functional complications. Patients will have to suffer of chronic constipation, inadequate weight gain and parental anxiety for a greater time [5]. Posterior Sagittal Anorectoplasty (PSARP), introduced by Alberto Pena, became widely accepted as the standard approach for the treatment of all types of ARM [6], without or with colostomy depending on the type of defect. This approach allowed surgeons to see directly the complex anatomy and relations of the rectum and genitourinary system and also made them possible to repair these defects under direct vision.

\section{Materials and Methods}

Since 2010 we performed a combined retrospective and prospective analysis of 76 patients with anorectal malformations, diagnosed and treated at University Clinical Centre of Kosovo between 2005 and 2014. Retrospective part of this study was completed using patients' records and database of Clinic of Pediatric Surgery and Clinic of Neonatology. In prospective part of our study we recorded new patients, gathering more qualitative data of their clinical features, associated anomalies and intraoperative details. Very close cooperation was established with pediatricians so we could see many patients suffering from chronic constipation among whom we found 18 new cases with anorectal malformations without previously established diagnosis. All cases were classified as low type defects according to Wingspread classification. Otherwise, Krickenbeck diagnostic criteria were used for diagnosis of ARMs and also for evaluation of postoperative constipation, voluntary bowel movements and soiling. Anal Position Index (API) was estimated in patients with anal stenosis to determine if there was anterior dislocation of the anus present or not. PSARP or minimal PSARP was performed in children with misplaced anus while in patients without anal displacement Cut Back procedure was performed. Data for postoperative constipation were collected starting as early as possible in life, since the parents reported it. Voluntary bowel movements and soiling were evaluated in patients older than 3 years of age.

\section{Results}

Of 76 diagnosed and treated patients with ARM at our Clinic during 10 years period 18 (23.68\%) were diagnosed beyond the neonatal period and they are analyzed in this study (Table 1). 11 were female (61.11\%) and 7 were male patients (38.89\%). All patients had low type defects. Anal stenosis was the most frequent malformation which appeared in 16 patients (88.89\%). It was found in 10 female and 6 male patients. Perineal fistula was seen in a male patient (5.56\%) and vestibular fistula in a female patient (5.56\%).

The age of the patients at the time of diagnosis varied from 3 months to 8.5 years. The average age of patients at the time of establishing the diagnosis was 25.67 months. 7 patients (38.89\%) were diagnosed during the first year of life, 5 other patients (27.78\%) during the second year of life and 4 patients (22.22\%) during the third year. Diagnosis was established at the age of 7 years in 1 patient while the last patient was diagnosed at the age of 8.5 (Chart 1$)$.

In total 6 associated anomalies were seen in 6 patients (33.33\%). 2 patients had cardiac associated anomalies (VSD), 3 patients had urogenital anomalies (1 undescended testis, 1 VUR and 1 ureter duplex) and one patient was diagnosed with osteo-articular anomaly (pes calcaneovalgus). 4 associated anomalies (66.67\%) were present in female patients while in male we found two anomalies.

All patients were treated primarily without colostomy. PSARP or minimal PSARP was performed in 10 patients (55.56\%). It was the procedure of choice in 8 patients with anal stenosis and anteriorly displaced anus, one patient with vestibular fistula and one patient with perineal fistula. Cut Back procedure was performed in 8 other patients (44.44\%) with anal stenosis without anal displacement. 
Table 1. Patients with late diagnosis of anorectal malformations.

\begin{tabular}{|c|c|c|c|c|c|c|}
\hline Nr. & $\begin{array}{l}\text { Age at diagnosis } \\
\text { (months) }\end{array}$ & Sex & Symptoms & Diagnosis & Associated anomalies & $\begin{array}{l}\text { Performed } \\
\text { operation }\end{array}$ \\
\hline 1 & 3 & M & Constipation. & Anal stenosis & & Minimal PSARP \\
\hline 2 & 5 & M & $\begin{array}{c}\text { Constipation. } \\
\text { Abdominal distension. }\end{array}$ & Perineal fistula & & PSARP \\
\hline 3 & 6 & $\mathrm{~F}$ & $\begin{array}{c}\text { Constipation. } \\
\text { Abdominal distension. }\end{array}$ & Anal stenosis & VUR & Minimal PSARP \\
\hline 4 & 8 & M & $\begin{array}{c}\text { Constipation. } \\
\text { Abdominal distention. }\end{array}$ & Anal stenosis & & Cut Back \\
\hline 5 & 8 & M & $\begin{array}{l}\text { Constipation. } \\
\text { Anal bleeding. }\end{array}$ & Anal stenosis & Undescended testis & PSARP \\
\hline 6 & 10 & M & Constipation. & Anal stenosis & & Minimal PSARP \\
\hline 7 & 12 & $\mathrm{~F}$ & Constipation. & Anal stenosis & & Minimal PSARP \\
\hline 8 & 14 & $\mathrm{~F}$ & $\begin{array}{l}\text { Constipation. } \\
\text { Urinary infection. }\end{array}$ & Vestibular fistula & & PSARP \\
\hline 9 & 16 & $\mathrm{~F}$ & $\begin{array}{l}\text { Constipation. } \\
\text { Anal bleeding. }\end{array}$ & Anal stenosis & & Cut Back \\
\hline 10 & 18 & $\mathrm{~F}$ & $\begin{array}{l}\text { Constipation. } \\
\text { Anal bleeding. }\end{array}$ & Anal stenosis & $V S D$ & Minimal PSARP \\
\hline 11 & 20 & $\mathrm{~F}$ & Constipation. & Anal stenosis & & PSARP \\
\hline 12 & 24 & $\mathrm{~F}$ & $\begin{array}{l}\text { Constipation. } \\
\text { Anal bleeding. }\end{array}$ & Anal stenosis & & Cut Back \\
\hline 13 & 30 & $\mathrm{~F}$ & $\begin{array}{l}\text { Constipation. } \\
\text { Anal bleeding. }\end{array}$ & Anal stenosis & & Cut Back \\
\hline 14 & 30 & M & $\begin{array}{l}\text { Constipation. } \\
\text { Anal bleeding. }\end{array}$ & Anal stenosis & & Cut Back \\
\hline 15 & 36 & $\mathrm{~F}$ & Constipation. & Anal stenosis & VSD & Minimal PSARP \\
\hline 16 & 36 & $\mathrm{~F}$ & Constipation. & Anal stenosis & Ureter duplex & Cut Back \\
\hline 17 & 84 & M & Constipation. & Anal stenosis & $\begin{array}{c}\text { Pes } \\
\text { calcaneovalgus }\end{array}$ & Cut Back \\
\hline 18 & 102 & $\mathrm{~F}$ & Constipation. & Anal stenosis & & Cut Back \\
\hline
\end{tabular}

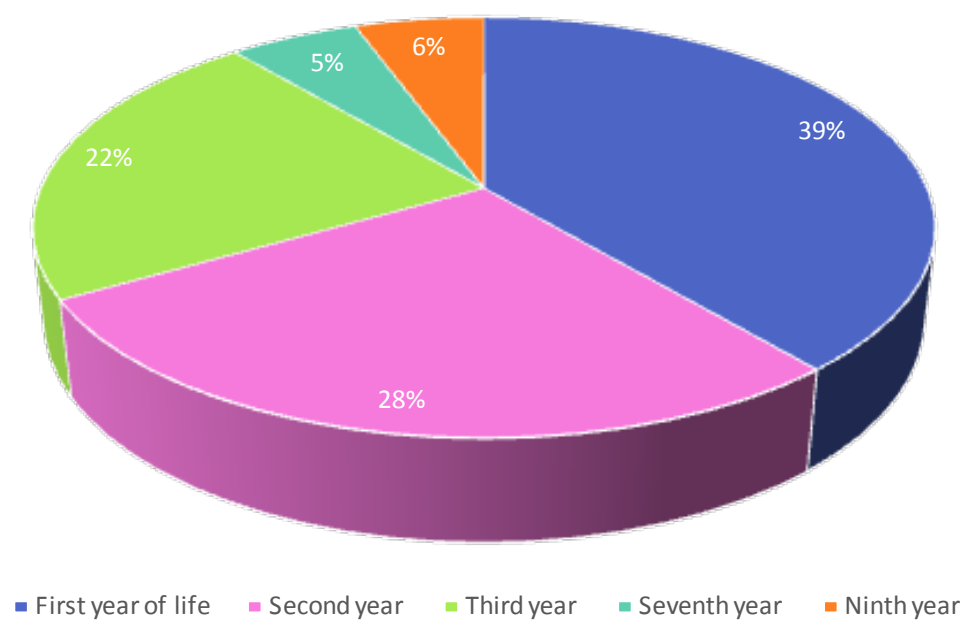

Chart 1. Age of the patients at the time of diagnosis.

Postoperative constipation appeared occasionally in 11 patients (61.11\%) of whom 4 males and 7 female patients. Only 2 patients had constipation of grade 1 (manageable by dietary modulations) while in 9 other patients constipation of grade 2 was observed occasionally (need for laxatives). 
Voluntary bowel movements and soiling were analyzed in a group of 13 patients older than 3 years of age, according to Krickenbeck recommendations. Voluntary bowel movements were present in all patients, but 5 of them (38.46\%) have soiling occasionally, therefore totally continent were considered $61.54 \%$.

\section{Discussion}

Careful perineal examination during neonatal examination within $24 \mathrm{hr}$ of birth is very important because it is the key point on identifying the most of ARMs. But as we can see in literature [5] [7]-[9] and also in our study, there is a considerable number of patients with ARM which are diagnosed later on life. During this study we have established a very close cooperation with pediatricians and consequently we have seen many patients suffering from chronic constipation among whom we found 18 "delayed" cases with anorectal malformations. This is the reason why in our 10 years study among 76 patients with ARM, anal stenosis was the most frequent malformation. Expressions like "delayed presentation" or "late diagnosis" of ARM are used by different authors for patients who presented beyond 24 hours of birth [10] [11], 48 hours of birth [5] [12], 7 days of birth and beyond 6 months of age for female patients with low-type ARM [8]. Some of them continue to live with ARM suffering of constipation or sometimes with fecal incontinence till adulthood [13] without recognizing the real cause of their complaints. Delay in establishing of diagnosis consequently delays proper treatment and increases the rate of morbidity and mortality [7].

Patients with delayed diagnosis represent $23.68 \%$ of 76 analyzed patients with ARM during 10 years study which is similar to the findings of Tareen et al. [5] and less than the findings of Haider [7] in their studies. In our, study the earliest diagnosed patient was a boy of 3 months of age (Table 1, Patient 1 ) with stenotic and anteriorly displaced anus presenting with constipation and abdominal distension, while the latest diagnosed patient was a female of 8.5 years of age (Table 1, Patient 9) also with anal stenosis. Most of our patients (39\%) were diagnosed during their first year of life, while in subsequent years their number has decreased (Chart 2).

Anal stenosis was the main diagnosis in our series and constituted $88.89 \%$ of all patients $(\mathrm{N}=16)$. During physical examination we found that anus was located anterior to its normal position in 8 patients (5 female and 3 male patients). Anal Position Index (API) described by Reisner et al. [14] as a simple method to measure the normal position of the anus as used to verify anterior displacement of the anus in our patients. The API is defined as the ratio between the fourchette-anal and fourchette-coccygeal distances in females and the scroto-anal and scroto-coccygeal distances in males. Although all our patients were diagnosed after neonatal period we used API according to the reports that there is no significant correlation of API with age [15]. In all 8 patients with misplaced anus API resulted to be lower than 0.34 in females and lower than 0.46 in males.

Symptoms were characterized by marked difficulty in passing stools, abdominal distension, perineal pain, urinary infection and sometimes anal bleeding as a consequence of anal fissures. Constipation was the symptom presenting to all of our patients which began in the first 3 months of life. Constipation was reported to be a symptom of such anomalies also in other series by other authors [16] [17]. Abdominal distension was seen in three patients and it was the key factor that has forced parents to consult a pediatric surgeon and led to the diagnosis. Anal bleeding happened in six patients and just like the abdominal distension it led us towards the diagnosis. Urinary infection was diagnosed in the only patient with vestibular fistula. In all patients treatment with stool softeners and other laxatives has been unsuccessful.

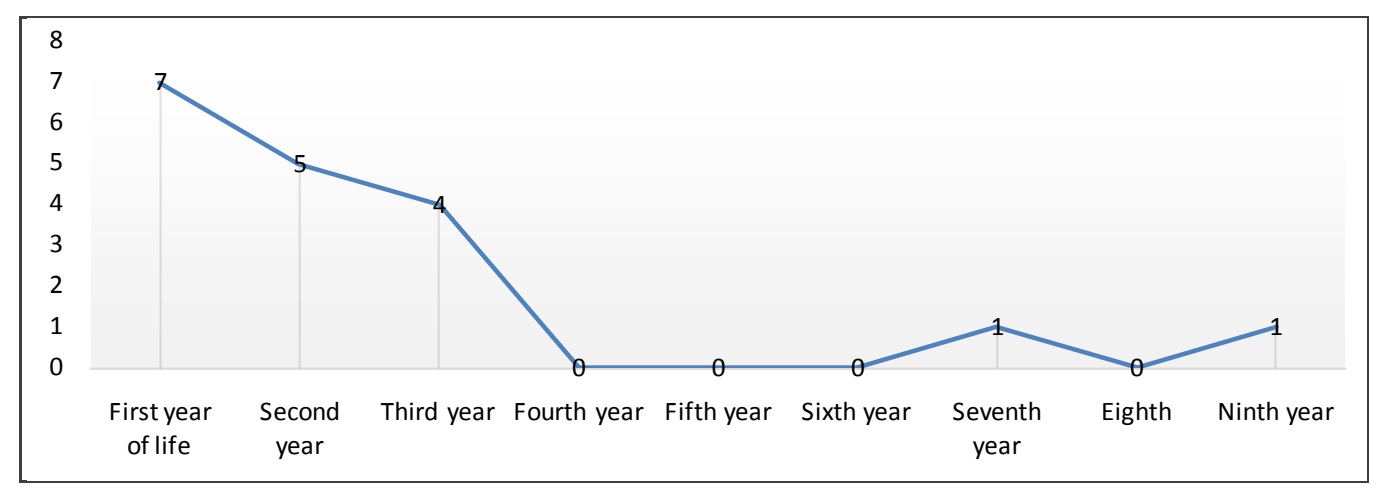

Chart 2. Age of the patients with late diagnosis of ARM. 
PSARP was performed in the treatment of 2 patients with more significant anterior displacement of the anus as well as in patients with vestibular fistula and perineal fistula (Table 1, Patients 2, 5, 8 and 11). Six other patients with anal stenosis were treated with minimal PSARP. Cut Back procedure was performed in 8 patients with anal stenosis in which the position of the anus was normal. In recent years our intention was to minimalize the use of Cut Back procedure and perform minimal PSARP instead of it because of widely accepted advantages of posterior sagittal approach. All patients have been treated in one stage, without colostomy. Postoperative recovery was normal at all patients of this group including intravenous antibiotics. There were no postoperative early complications. In all cases operated with PSARP we have applied anal dilatations to avoid postoperative stenosis.

Morbidity after operative treatment consists on occasional constipation and occasional soiling. 11 patients have experienced occasional episodes of postoperative constipation which have been managed by dietary modulations in two patients, and use of laxatives in nine patients (grade 1 and grade 2 of constipation according to Krickenbeck classification). Parents are advised to be careful with their children's diet and are informed about the importance of prevention of constipation after surgical treatment.

13 patients older than 3 years of age were analyzes for voluntary bowel movements and soiling using the Krickenbeck criteria. Voluntary bowel movements were present in all patients. Parents of 5 patients (38.46\%) have reported occasional soiling of grade 1. Four patients of this group have been treated with Cut Back procedure because of anal stenosis (Table 1, Patients 9, 12, 13 and 17). The fifth patient underwent PSARP procedure because of anteriorly displaced anus and stenosis (Table 1, Patient 11). Later on, when the patients were 6 - 7 years old, the parents of three children reported that the leakage had reduced by a large amount and only rarely occurred anymore (Table 1, Patient 11, 13 and 17). We believe that the older a child gets the more control they achieve over their bowel movements. On this issue there are different standpoints of different authors. Traditionally, it has been said that one has to wait 12 to 13 years before one can have a real evaluation of patients subjected to a repair of an anorectal malformation [18]. On the other hand Kiely and Pena do not believe that children have better fecal control as time passes [19]. Reports of different authors about the incidence of incontinence in low type ARMs vary, ranging between 0\% up to 42\% [20]-[22].

\section{Conclusion}

Delayed diagnosis of ARM seems to be an underestimated issue in many countries. Reports of complications and mortality due to this delay highlight the importance of review of current practices during the examination of newborn babies by neonatologists and pediatric surgeons. Therefore, a careful, comprehensive clinical examination of the newborn's perineum is essential on preventing the failure of diagnosis of ARM at the early neonatal age. Later in life, all patients with severe and chronic constipation must be evaluated for eventually missed diagnosis of anorectal malformations. We encourage pediatricians and other physicians caring for the health of children not to hesitate to ask a pediatric surgeon's consultation for children with chronic constipation.

\section{Conflict of Interest}

The authors declare that there is no conflict of interests regarding the publication of this manuscript.

\section{References}

[1] Gangopadhyay, A.N. and Pandey, V. (2015) Anorectal Malformations. Journal of Indian Association of Pediatric Surgeons, 20, 10-15. http://dx.doi.org/10.4103/0971-9261.145438

[2] Levitt, M.A. and Peña, A. (2010) Imperforate Anus and Cloacal Malformations. Ashcraft's Pediatric Surgery. 5th Edition, Saunders Elsevier, Philadelphia, 468-490. http://dx.doi.org/10.1016/B978-1-4160-6127-4.00036-7

[3] Holschneider, A., Hutson, J., Pena, A., et al. (2005) Preliminary Report on the International Conference for the Development of Standards for the Treatment of Anorectal Malformations. Journal of Pediatric Surgery, 40, 1521-1526. http://dx.doi.org/10.1016/j.jpedsurg.2005.08.002

[4] Pena, A. (1988) Surgical Treatment of Female Anorectal Malformations. Birth Defects Original Article Series, 24, 403-423.

[5] Tareen, F., Coyle, D., Aworanti, O.M. and Gillick, J. (2013) Delayed Diagnosis of Anorectal Malformation-A Persistent Problem. Irish Medical Journal, 106, 238-240.

[6] De Vries, P.A. (2001) Posterior Sagittal Anorectoplasty. Journal of Paediatric Surgery, 17, 638-643. 
http://dx.doi.org/10.1016/S0022-3468(82)80126-7

[7] Haider, N. and Fisher, R. (2007) Mortality and Morbidity Associated with Late Diagnosis of Anorectal Malformations in Children. Surgeon, 5, 327-330. http://dx.doi.org/10.1016/S1479-666X(07)80083-7

[8] Sinha, S.K., Kanojia, R.P., Wakhlu, A., Rawat, J.D., Kureel, S.N. and Tandon, R.K. (2008) Delayed Presentation of Anorectal Malformations. Journal of Indian Association of Pediatric Surgeons, 13, 64-68. http://dx.doi.org/10.4103/0971-9261.43023

[9] Miglani, R.K., Murthy, D., Bhat, R.S., Ashok, K.K., Lindley, R.M., Shawis, R.N. and Roberts, J.P. (2006) Delays in the Diagnosis of Anorectal Malformations Are Common and Significantly Increase Serious Early Complications. Acta Paediatrica, 95, 364-368. http://dx.doi.org/10.1080/08035250500437523

[10] Wilson, B.E., Etheridge, C.E., Soundappan, S.V. and Holland, A.J. (2010) Delayed Diagnosis of Anorectal Malformations: Are Current Guidelines Sufficient? Journal of Paediatrics and Child Health, 46, 268-272. http://dx.doi.org/10.1111/j.1440-1754.2009.01683.x

[11] Lindley, R.M., Shawis, R.N. and Roberts, J.P. (2006) Delays in the Diagnosis of Anorectal Malformations Are Common and Significantly Increase Serious Early Complications. Acta Paediatrica, 95, 364-368.

[12] Eltayeb, A.A. (2010) Delayed Presentation of Anorectal Malformations: The Possible Associated Morbidity and Mortality. Pediatric Surgery International, 26, 801-806. http://dx.doi.org/10.1007/s00383-010-2641-2

[13] Miglani, R.K., Murthy, D., Bhat, R.S. and Ashok, K.K. (2012) Anorectal Anomalies in Adults-Laparoscopic Management and Review of Literature. Indian Journal of Surgery, 74, 301-304. http://dx.doi.org/10.1007/s12262-011-0394-3

[14] Reisner, S.H., Sivan, Y., Nitzan, M. and Merlob, P. (1984) Determination of Anterior Displacement of the Anus in Newborn Infants and Children. Pediatrics, 73, 216-217.

[15] Mohta, A. and Goel, M.R. (2004) Determination of Anal Position Index. Indian Pediatrics, 41, 91-92.

[16] Nancy, K.H.L., Gow, K.W., Penner, J.G., Blair, G.K., Murphy, J.J. and Webber, E.M. (2000) Presentation of Low Anorectal Malformations beyond the Neonatal Period. Pediatrics, 105, E68. http://dx.doi.org/10.1542/peds.105.5.e68

[17] Ishitani, M.B. and Rodgers, B.M. (1991) Anteriorly Displaced Anus: An Under-Recognized Cause of Chronic Constipation. Pediatric Surgery International, 6, 217-220. http://dx.doi.org/10.1007/BF00176073

[18] Harjai, M.M., Puri, B., Vincent, P.J. and Nagpal, B.M. (2003) Fecal Incontinence after Posterior Sagittal Anorectoplasty_Follow up of 2 Years. Medical Journal Armed Forces India, 59, 194-196.

[19] Kiely, E.M. and Pena, A. (1998) Anorectal Malformations. In: O’Neill Jr., J.A., Rowe, M.I., Grosfeld, J.L., Fon-Kalsrud, E.W. and Coran, A.G., Eds., Paediatric Surgery, 5th Edition, Mosby-Year Book, Inc., St. Louis, 1425-1448.

[20] Kamal, J.S., Rayes, O.M., Kurdi, M.O., Abdulhaleem, A.R. and Farsi, M. (2012) A Collective Review of Cases with Imperforate Anus Managed in a Teaching Hospital. Saudi Journal for Health Sciences, 1, 122-125. http://dx.doi.org/10.4103/2278-0521.106080

[21] Stenström, P., Kockum, C.C., Emblem, R., Arnbjörnsson, E. and Bjørnland, K. (2014) Bowel Symptoms in Children with Anorectal Malformation-A Follow-Up with a Gender and Age Perspective. Journal of Pediatric Surgery, 49, 1122-1130. http://dx.doi.org/10.1016/j.jpedsurg.2013.10.022

[22] Pakarinen, M.P. and Rintala, R.J. (2010) Management and Outcome of Low Anorectal Malformations. Pediatric Surgery International, 26, 1057-1063. http://dx.doi.org/10.1007/s00383-010-2697-z 